\title{
Biosorption studies on waste cotton seed for cationic dyes sequestration: equilibrium and thermodynamics
}

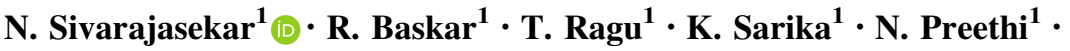 \\ T. Radhika ${ }^{1}$
}

Received: 8 August 2015/Accepted: 4 January 2016/Published online: 30 January 2016

(C) The Author(s) 2016. This article is published with open access at Springerlink.com

\begin{abstract}
The immature Gossypium hirsutum seeds-an agricultural waste was converted into a novel adsorbent and its effectiveness for cationic dyes removal was discussed in this study. Characterization revealed that sulfuric acid activated waste Gossypium hirsutum seed (WGSAB) contains surface area $496 \mathrm{~m}^{2} \mathrm{~g}^{-1}$. The ability of WGSAB to adsorb basic red 2 (BR2) and basic violet 3 (BV3) from aqueous solutions has been studied. Batch adsorption studies were carried out at different initial dye concentrations (100-300 $\mathrm{mg} \mathrm{l}^{-1}$ ), contact time (1-5 h), pH (2-12) and temperature (293-323 K) to understand the adsorption mechanism. Adsorption data were modeled using Langmuir, Freundlich and Toth adsorption isotherms. Equilibrium data of the adsorption process fitted very well to the Toth model for both dyes. The Langmuir maximum adsorption capacity was $66.69 \mathrm{mg} \mathrm{g}^{-1}$ for BV3 and $50.11 \mathrm{mg} \mathrm{g}^{-1}$ for BR2 at optimum conditions. The near unity value of Toth isotherm constant (BR2: 0.999 and BV3: 1.0) indicates that WGSAB surface is heterogeneous in nature. The maximum adsorption capacity predicted by Toth isotherm of BV3 (66.699 $\left.\mathrm{mg} \mathrm{g}^{-1}\right)$ is higher than BR2 $\left(50.310 \mathrm{mg} \mathrm{g}^{-1}\right)$. The kinetic investigation revealed that the BR2 and BV3 were chemisorbed on WGSAB surface following Avrami fractional order kinetics. Further, the fractional order and rate constant values are almost similar for every concentration in both the dyes. The thermodynamic parameters such as $\Delta H^{0}, \Delta S^{0}$ and $\Delta G^{0}$ were evaluated. The dye adsorption process was found to be spontaneous and endothermic for the two dyes.
\end{abstract}

N. Sivarajasekar

sivarajasekar@gmail.com

1 Department of Chemical Engineering, Kongu Engineering College, Perundurai, Erode 638052, Tamil Nadu, India
Regeneration of WGSAB exhausted by the two dyes could be possible via acetic acid as elutant.

Keywords Adsorption - Gossypium hirsutum seed · Isotherm · Kinetic · Thermodynamic

\section{List of symbols}

$\Delta G^{0} \quad$ Gibbs free energy change $\left(\mathrm{J} \mathrm{mol}^{-1}\right)$

$\Delta H^{0} \quad$ Enthalpy change $\left(\mathrm{J} \mathrm{mol}^{-1}\right)$

$\Delta S^{0} \quad$ Entropy change $\left(\mathrm{J} \mathrm{mol}^{-1} \mathrm{~K}^{-1}\right)$

$b_{\mathrm{L}} \quad$ Langmuir model constant $\left(1 \mathrm{mg}^{-1}\right)$

$C_{0} \quad$ Final concentration $\left(\mathrm{mg} \mathrm{l}^{-1}\right)$

$C_{\mathrm{i}} \quad$ Initial and final concentration $\left(\mathrm{mg} \mathrm{l}^{-1}\right)$

$C_{t} \quad$ Concentration at any time $t$

$h \quad$ Ho initial sorption rate $\left(\mathrm{mg} \mathrm{g}^{-1} \min ^{-1}\right)$

$k_{\mathrm{A}} \quad$ Avrami rate constant $\left(\mathrm{min}^{-1}\right)$

$K_{\mathrm{F}} \quad$ Freundlich isotherm constant $\left(\mathrm{l} \mathrm{g}^{-1}\right)$

$k_{\mathrm{Ho}} \quad$ Ho rate constant $\left(\mathrm{g} \mathrm{mg}^{-1} \mathrm{~min}^{-1}\right)$

$K_{\mathrm{T}} \quad$ Toth isotherm constant

$M \quad$ Amount of WGSAB (g)

$n_{\mathrm{A}} \quad$ Avrami model exponent

$N_{\mathrm{F}} \quad$ Freundlich exponent

$n_{\mathrm{T}} \quad$ Toth isotherm exponent

$q_{e, \mathrm{Ho}}$ Biosorption capacity from Ho equation $\left(\mathrm{mg} \mathrm{g}^{-1}\right)$

$q_{\mathrm{mL}} \quad$ Langmuir maximum monolayer biosorption capacity ( $\left.\mathrm{mg} \mathrm{g}^{-1}\right)$

$q_{\mathrm{mT}} \quad$ Toth maximum monolayer biosorption capacity $\left(\mathrm{mg} \mathrm{g}^{-1}\right)$

$q_{t} \quad$ Dye adsorption capacity $\left(\mathrm{mg} \mathrm{g}^{-1}\right)$

$R \quad$ Gas constant $\left(8.314 \mathrm{~J} \mathrm{~mol}^{-1} \mathrm{~K}^{-1}\right)$

$R_{\mathrm{L}} \quad$ Separation factor

$T \quad$ Absolute temperature (K)

$t \quad$ Time (min)

$V \quad$ Volume of dye solution (1)

$\lambda_{\text {max }}$ Optical density 


\author{
Abbreviations \\ BET Breuner-Emmet-Teller \\ BR2 Basic red 2 \\ BV3 Basic violet 3 \\ FTIR Fourier Transform Infra Red \\ SEM Scanning electron microscope
}

\section{Introduction}

Process industries such as paper, textile, plastic, leather, cosmetic, and food employ dyes to color their products. The residual dye bearing effluents of those processes are discharged into the water bodies as such (Rangabhashiyam et al. 2013; Sivarajasekar et al. 2008, 2009). Among, the variety of dyes (cationic, anionic and neutral), the cationic dye is more toxic (Sivarajasekar et al. 2008; Sivarajasekar and Baskar 2013). These dyes have been reported to cause allergy, irritation, cancer and even mutation in human beings (Sepúlveda-Cuevas Luisa et al. 2008; Sivarajasekar and Baskar 2014a). Hence, the removal of these dyes from effluents before discharge to public water sources is an urgent and challenging requirement.

Adsorption is generally realized as an effective technique for the treatment of dye-containing wastewater (Rangabhashiyam et al. 2014; Akar et al. 2013). Among the different adsorbents identified, activated carbon was generally preferred in removal of dyes from waste water due to its relatively high sorption capacity for a wide variety of dyes. Commercially available activated carbons obtained from either wood or coal are usually expensive (Sivarajasekar and Baskar 2014b) and therefore, developing cost-effective adsorbent will encourage the industries to employ adsorption as a primary process for waste water treatment. Recently, the research has being focused toward production of activated carbon from agricultural byproducts and waste materials (Sivarajasekar 2007; Srinivasan et al. 2010; Ramaraju et al. 2014). Agricultural byproducts or wastes are rich source of organic matter containing hydroxyl, carboxyl and amine groups which can easily facilitate binding of cations such as cationic dyes (Sivarajasekar and Baskar 2015a).

Cotton (Gossypium hirsutum) is one of the industrial crops which plays a major role in the economics of many countries. India is the third largest country in the world which produces cotton approximately $6 \times 10^{3}$ tons per year (Sivarajasekar and Baskar 2015b). After harvest, the cotton seeds separated from cotton fibers are used for oil extraction. The immature cotton seeds unfit for germination and oil extraction are discarded as waste in large quantity, in India (Sivarajasekar 2014). To best of our knowledge this cheap and renewable waste material is not yet tried by the researchers as a source material for adsorbent preparation.
Therefore, in this study, an attempt was made to prepare a novel adsorbent from waste Gossypium hirsutum seeds, characterize it and investigate its adsorption potential for two different cationic dyes namely, basic red 2 and basic violet 3 . Detailed isotherm and kinetic studies to understand the mechanism of dye adsorption were also reported.

\section{Materials and methods}

\section{Preparation of dye solution}

Basic red 2 (BR2) and Basic violet 3 (BV3) were obtained from S.D. Fine Chemicals Ltd, Mumbai. All other chemicals were obtained from Merck India Ltd, Mumbai. The structure of BR2 and BV3 is shown in Fig. 1. The stock solution of dye was prepared by dissolving $1 \mathrm{~g}$ of dye in 11 of deionized water. All working solutions were prepared by diluting the stock solution to the desirable concentration. The initial $\mathrm{pH}$ of working solution was adjusted to the experimental conditions by stepwise adding of $0.1 \mathrm{~N} \mathrm{HCl}$ or $0.1 \mathrm{~N} \mathrm{NaOH}$ solutions before mixing the adsorbent with the dye solution. The concentration of dye in the sample was analyzed using a double beam UV-Vis spectrophotometer (ELICO-SL244, India) at its maximum wavelength.

\section{Activated biomass preparation}

Waste Gossypium hirsutum seeds were obtained from seed manufacturers, Tamil Nadu, India. The collected seeds were washed thoroughly and dried at $313 \mathrm{~K}$ in a temperature controlled oven for 3 days. The dried biomass was soaked with concentrated sulfuric acid in the weight ratio of 1:4. The acid soaked biomass was stirred occasionally and kept for $12 \mathrm{~h}$ to achieve complete adsorption of $\mathrm{H}_{2} \mathrm{SO}_{4}$. The resultant black slurry was carefully washed with deionized water and $0.1 \mathrm{~N}$ sodium bicarbonate solution to remove the traces of acid. The resultant material,

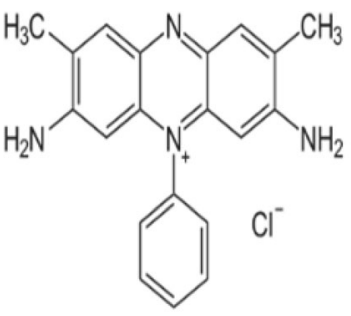

(a) Basic Red 2

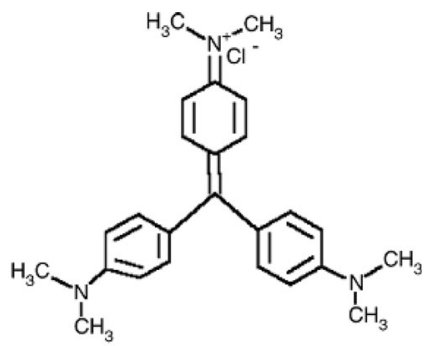

(b) Basic Violet 3
Fig. 1 Details of the cationic dyes: a basic red 2-CI: 50,240, molecular weight: $350.84 \mathrm{~mol}, \lambda_{\max }: 543 \mathrm{~nm}$; b basic violet $3-\mathrm{CI}$ : 42,555, molecular weight: $407.98 \mathrm{~mol}, \lambda_{\max }: 591 \mathrm{~nm}$ 
waste Gossypium hirsutum seed activated biomass (WGSAB), was dried, finely ground, and stored in an air tight container for subsequent adsorption experiments.

\section{Characterizations of WGSAB}

The iodine and methylene blue numbers of WGSAB were calculated based on the ASTM 4607-86 standards at $298 \mathrm{~K}$. The specific surface area of WGSAB was measured using a surface analyzer (Micromeritics ASAP 2020). Surface morphology was examined using a scanning electron microscope (SEM: JSM-6390LV-JEOL Ltd., Japan). Surface functional groups were determined based on a Boehm titration method. The surface $\mathrm{pH}$ of the WGSAB was determined by adding $1 \mathrm{~g}$ of carbon to $100 \mathrm{ml}$ of deionized water and agitated at room temperature for $24 \mathrm{~h}$. The supernatant liquid was centrifuged and $\mathrm{pH}$ was noted as the $\mathrm{pH}$ of WGSAB. Zero surface charge was found using solid addition method. FTIR analysis was done using a Thermo Nicolet, Avatar 370 FTIR spectrometer over a spectral range of $4000-400 \mathrm{~cm}^{-1}$ at a resolution of $4 \mathrm{~cm}^{-1}$.

\section{Batch adsorption}

Batch adsorption experiments were conducted for the selected parameter ranges such as $\mathrm{pH}(2-12)$, temperature (293-313 K), initial concentration (100-300 $\mathrm{mg} \mathrm{l}^{-1}$ ) and contact time (1-5 h). Known amount of adsorbent was agitated with $200 \mathrm{ml}$ of dye solution taken in Erlenmeyer flasks by means of a thermo-regulated shaker (GeNei SLM-IN-OS-16, India) operating at $100 \mathrm{rpm}$. The samples were withdrawn from the flasks at predetermined time intervals for kinetic experiments and at equilibrium time for isotherm studies. Collected samples were centrifuged and analyzed for the residual dye concentration using double beam UV-Vis spectrophotometer (ELICO-SL244, India). Experiments were repeated 3 times to obtain accurate data. Percentage of dye removal from bulk dye solution was calculated using the following equation:

$\% R=\frac{C_{i}-C_{0}}{C_{i}} \times 100$

where $C_{\mathrm{i}}$ and $C_{0}\left(\mathrm{mg} \mathrm{l}^{-1}\right)$ are initial and final concentrations of the dye in the aqueous solution. The dye adsorption capacity $q_{\mathrm{t}}\left(\mathrm{mg} \mathrm{g}^{-1}\right)$ at any time $t$ was determined as

$q_{t}=\left(C_{i}-C_{t}\right) \times \frac{V}{M}$

where $C_{\mathrm{t}}\left(\mathrm{mg} \mathrm{l}^{-1}\right)$ is concentration of dye at any time $t$, $V(\mathrm{l})$ is volume of dye solution, and $M(\mathrm{~g})$ is amount of WGSAB. The exhausted WGSAB was regenerated using hot water, acetone, dilute hydrochloric acid and dilute acetic acid in order to find the suitable solvent.

\section{Isotherms}

The batch equilibrium data obtained for five different initial concentrations $\left(100,150,200,250\right.$ and $\left.300 \mathrm{mg} \mathrm{l}^{-1}\right)$ at $\mathrm{pH} 12$, temperature $313 \mathrm{~K}$ and contact time $180 \mathrm{~min}$ were fitted to following isotherms.

Langmuir (1918):

$q_{e}=\frac{q_{m L} b_{L} C_{e}}{1+b_{L} C_{e}}$

Freundlich (1932):

$q_{e}=K_{F} C_{e}^{1 / n_{\mathrm{F}}}$

Toth (1971):

$q_{e}=\frac{q_{m T} C_{e}}{\left(K_{T}+C_{e}^{n_{\mathrm{T}}}\right)^{n_{\mathrm{T}}}}$

\section{Kinetics}

Batch experiments were carried out for different concentrations $\left(100,150,200,250\right.$ and $\left.300 \mathrm{mg} \mathrm{l}^{-1}\right)$ with $\mathrm{pH} \mathrm{12,}$ temperature $313 \mathrm{~K}$ and contact time $180 \mathrm{~min}$ to investigate the kinetics. Kinetic equations including Ho and Avrami were employed for testing the batch kinetic data.

Ho (2006):

$q_{t}=\frac{q_{e, H o}^{2} k_{H o} t}{1+k_{H o} q_{e} t}$

Avrami (Ho and McKay 2003):

$q_{t}=q_{e, A}\left[1+\exp \left(-k_{A} t\right)^{n_{A}}\right]$

\section{Thermodynamics}

Batch experiments were carried out for differential temperatures $(293,303,313$ and $323 \mathrm{~K}$ ) with $\mathrm{pH} 12$, initial concentration $150 \mathrm{mg} \mathrm{l}^{-1}$ and contact time $180 \mathrm{~min}$ to examine the thermodynamic parameters. They were calculated from following (Smith and Van Ness 1987) Eqs. 8-9:

$\ln \left(\frac{q_{e}}{C_{e}}\right)=\frac{\Delta S^{0}}{2.303 R}-\frac{\Delta H^{0}}{2.303 R T}$

$\Delta G^{0}=\Delta H^{0}-T \Delta S^{0}$

$\Delta H_{\mathrm{is}}=\frac{d\left(\ln C_{e}\right)}{d(1 / T)}$

where $R$ is gas constant $\left(8.314 \mathrm{~J} \mathrm{~mol}^{-1} \mathrm{~K}^{-1}\right)$ and $T$ is the absolute temperature $(K)$. 


\section{Data analysis}

The isotherm and kinetic parameters were determined using MATLAB ${ }^{\circledR}$ non-linear curve fitting tool. The statistical parameters such correlation coefficient $\left(R^{2}\right)$ and root mean square error (RMSE) were considered for examining the correlations. The $R^{2}$ close to unity and smaller RMSE is the index to select the suitable correlation.

\section{Results and discussions}

\section{Characterization of WGSAB}

The amount of micropores (1.0-2.8 nm) developed on the carbon surface is estimated using Iodine number, whereas the development of mesopores (around $1.5 \mathrm{~nm}$ ) is understood via methylene blue number (Kasaoka et al. 1989). The Iodine number and methylene blue number of WGSAB were measured to be 510 and $42 \mathrm{mg} \mathrm{g}^{-1}$, respectively. The BET surface area was found to be $496 \mathrm{~m}^{2} \mathrm{~g}^{-1}$ which conferred the development of pores on its surface. The SEM micrograph (Fig. 2c) showed that the WGSAB surface was full of uneven sized micro pores due to effective chemical activation by sulfuric acid. In addition to the porosity, the reactive functional groups on the surface strongly influence biosorption behavior of the WGSAB. Boehm titration provides evidence for the existence of surface functional groups such as carboxylic, lactonic, phenolic and carbonyl contributing to surface acidity (Boehm 1966). The surface of the WGSAB was found to be chemically heterogeneous, and the basicity ( $1.24 \mathrm{mmol} \mathrm{g}^{-1}$ ) was less compared to the surface acidity (5.37 $\mathrm{mmol} \mathrm{g}^{-1}$ ). The surface $\mathrm{pH}$ was estimated to be 6.5 . The point of zero charge was estimated to be 6.4. The FTIR analysis (Figure not shown) revealed that WGSAB surface was comprised with $\mathrm{OH}\left(3419 \mathrm{~cm}^{-1}\right), \mathrm{COOH}$ (1704 and $\left.1625 \mathrm{~cm}^{-1}\right)$, and $\mathrm{S}=\mathrm{O}\left(1380 \mathrm{~cm}^{-1}\right)$ functional groups.

\section{Effect of pH}

To achieve a maximum dye removal by an adsorbent, the hydrogen ion concentration is to be monitored carefully in the adsorption process. It replaces some of the positive ions found in the active sites and alters the degree of ionization of the dye during the adsorption (Srinivasan and Viraraghavan 2010; Rafatullah et al. 2010; Amran et al. 2011). The effect of initial $\mathrm{pH}$ on the adsorption of $\mathrm{BV} 3$ and BV2 is represented in Fig. 2. The percentage of BV3 and BR2 sorption onto WGSAB showed an increasing trend as the $\mathrm{pH}$ changed from 2 via 12 . The percentage dye removal increased from 68.5 to $94 \%$ for BV3 and 65.5 to $90.26 \%$ for BR2. The maximum adsorption was found at $\mathrm{pH} 12$ for both the dyes. Cationic adsorption is favorable at $\mathrm{pH}$ value higher than surface $\mathrm{pH}$ (18). Hence, increase in the $\mathrm{pH}$ led reduction of $\mathrm{H}^{+}$ions concentration on the sorption sites and electrostatic attraction between the dye molecule and WGSAB which increased the percentage dye removal (Gupta and Suhas 2009; Rafatullah et al. 2010; Arslan and Yiğitoğlu 2008).

\section{Effect of temperature}

The effect of aqueous phase temperature on the adsorption of BV3 and BR2 is shown in Fig. 3. An increasing trend was noticed in percentage dyes removal while changing the solution temperature from 293 to $313 \mathrm{~K}$. Percentage dye removal increased from 74.9 to $94.9 \%$ for BV3 and 71.24 to $92.18 \%$ for BR2. This illustrated that adsorption of these dyes was endothermic and the raise in solution temperature promoted the kinetic energy of both the dyes which enhanced the rate of diffusion of dye molecules
Fig. 2 Details of adsorbent: a immature Gossypium histurum seeds, b WGSAB, c SEM micrograph of WGSAB

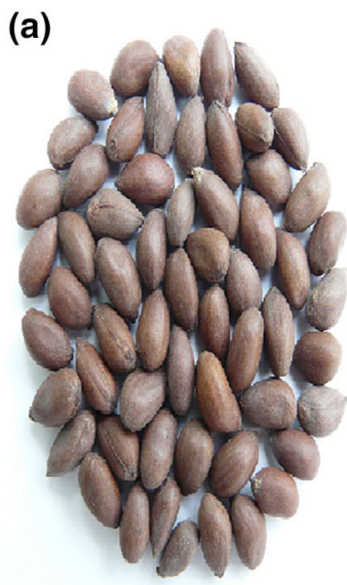



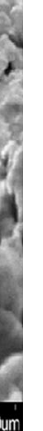

(b)

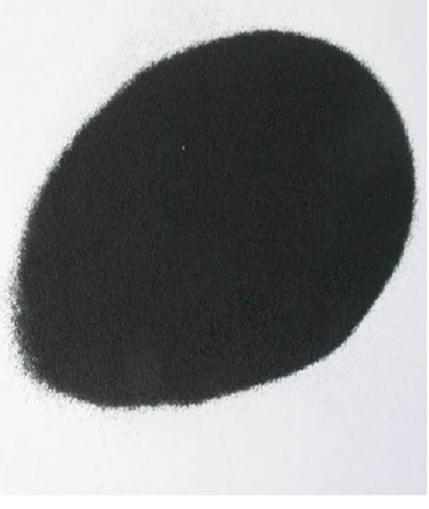




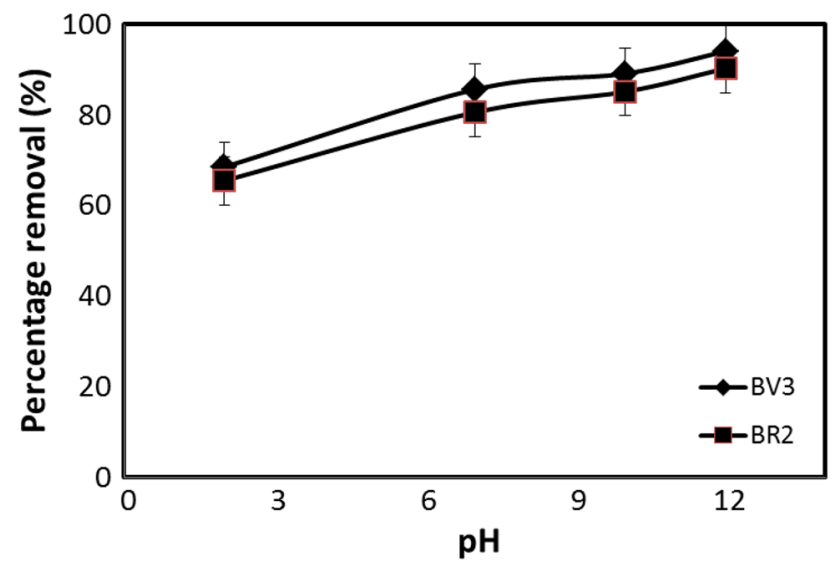

Fig. 3 Effect of $\mathrm{pH}$ on percentage dye removal (conditions: initial concentration: $150 \mathrm{mg} \mathrm{l}^{-1}$, dosage: $1 \mathrm{~g} \mathrm{l}^{-1}$, temperature: $303 \mathrm{~K}$, contact time: $360 \mathrm{~min}$ )

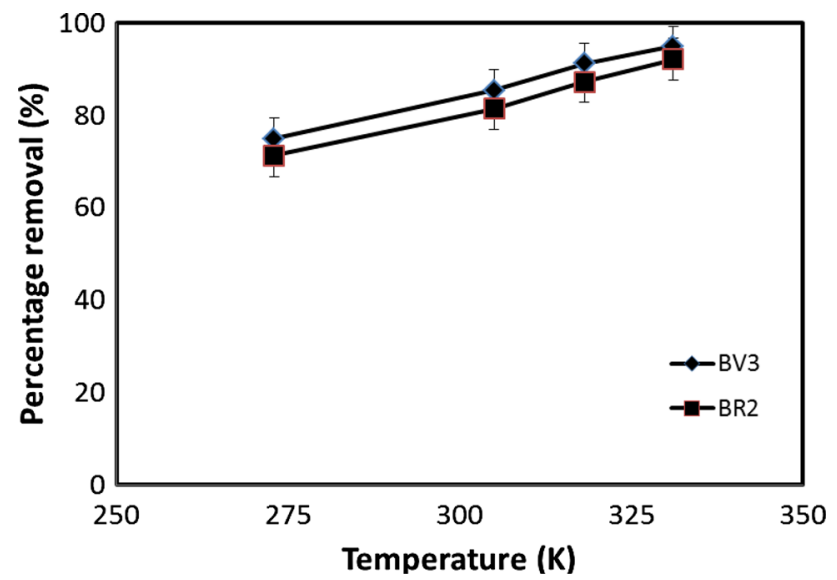

Fig. 4 Effect of temperature on percentage dye removal (conditions: initial concentration: $150 \mathrm{mg} \mathrm{l}^{-1}$, dosage: $1 \mathrm{~g}^{-1}, \mathrm{pH}$ : 12 , contact time: $360 \mathrm{~min}$ )

across the boundary layer and into the WGSAB pores (Farah et al. 2007; Rafatullah et al. 2010).

\section{Effect of initial concentration and contact time}

To find equilibrium time, the sorption of dyes onto WGSAB was observed as a function of time until the amount of dyes adsorbed became constant (Figs. 4, 5). Maximum percentage of dyes removal was noted within $30 \mathrm{~min}$ in both cases of dyes. This rapid adsorption uptake of dyes indicated the chemisorption nature of sorption onto WGSAB (Gulnaz et al. 2004). After this quick uptake the percentage dyes removal was gradually increased until $180 \mathrm{~min}$ and after there was only a slight difference in the percentage dyes removal. Hence, the equilibrium time was fixed to be $180 \mathrm{~min}$ for all experiments independent of the initial dyes concentrations. The percentage dyes removal
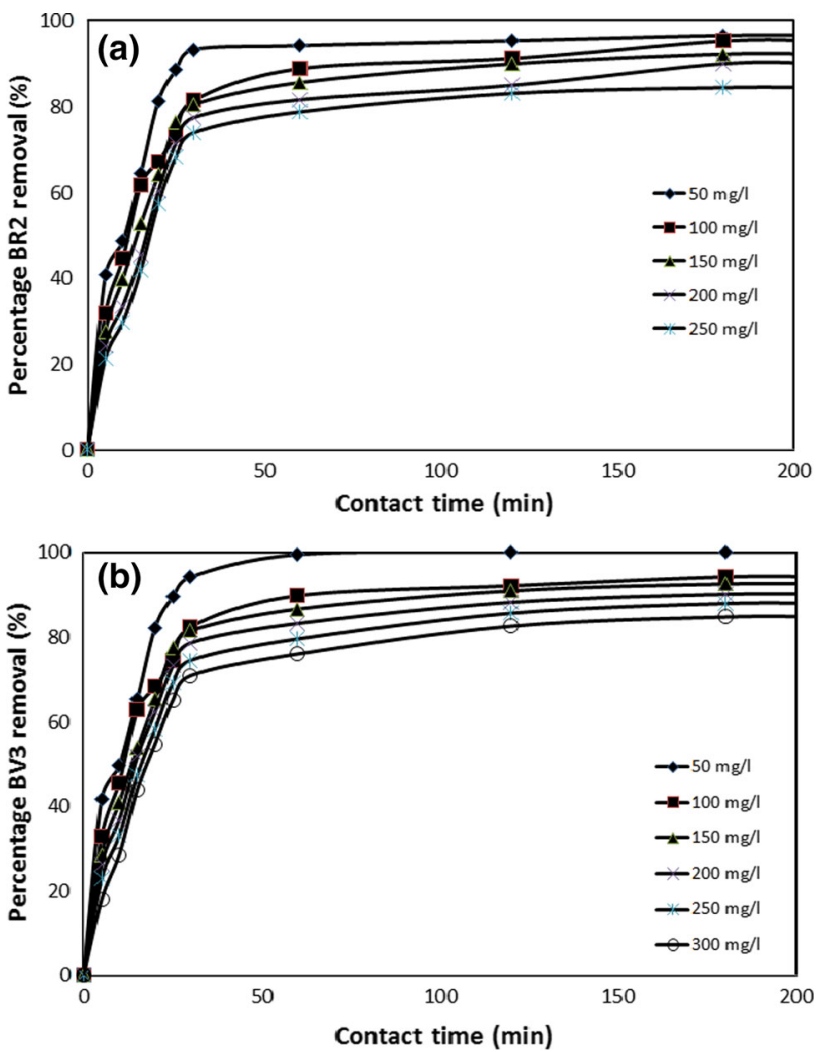

Fig. 5 Effect of initial concentration and contact time on percentage dye removal (conditions: contact time: $360 \mathrm{~min}$, dosage: $1 \mathrm{~g} \mathrm{l}^{-1}, \mathrm{pH}$ : 12, temperature: $313 \mathrm{~K}$ )

Table 1 Optimum parameters and statistical values for isotherms

\begin{tabular}{llcc}
\hline Isotherm & Constants & BR2 & BV3 \\
\hline Langmuir & $Q_{\mathrm{mL}}\left(\mathrm{mg} \mathrm{g}^{-1}\right)$ & 50.310 & 66.699 \\
& $b_{\mathrm{L}}\left(1 \mathrm{mg}^{-1}\right)$ & 0.126 & 0.065 \\
& $R_{\mathrm{L}}$ & 0.033 & 0.081 \\
& $R^{2}$ & 0.9906 & 0.9945 \\
\multirow{5}{*}{ Freundlich } & $\mathrm{RMSE}$ & 1.7805 & 1.3297 \\
& $K_{\mathrm{F}}\left(1 \mathrm{~g}^{-1}\right)$ & 8.688 & 8.705 \\
& $n_{\mathrm{F}}$ & 2.231 & 2.132 \\
& $R^{2}$ & 0.9697 & 0.9924 \\
Toth & $\mathrm{RMSE}$ & 3.1990 & 1.5618 \\
& $q_{\mathrm{mT}}\left(\mathrm{mg} \mathrm{g}^{-1}\right)$ & 50.105 & 66.699 \\
& $n_{\mathrm{T}}$ & 0.999 & 1.000 \\
& $R^{2}$ & 0.9907 & 0.9945 \\
& $\mathrm{RMSE}$ & 1.7738 & 1.3297 \\
\hline
\end{tabular}

onto WGSAB was decreased with the increase of initial dyes concentrations due to the boundary layer resistance (Garg et al. 2004; Malik 2003), unavailability of active sites and pores to dye molecules on WGSAB particles (Srinivasan and Viraraghavan 2010; Amran et al. 2011). 




Fig. 6 Comparison of isotherms

\section{Isotherms}

The optimum parameter set for each isotherm model, $R^{2}$ and RMSE values are displayed in Table 1. The goodness of the models to explain the equilibrium data was in the order: Toth $>$ Langmuir $>$ Freundlich. The Toth isotherm was developed from potential theory to enhance the outcomes of Langmuir isotherm and also to be applicable for heterogeneous sorption systems. The high values of $R^{2}$ and low values of RMSE indicate that Toth isotherm properly correlated the adsorption data better than other two isotherms. The near unity value of Toth isotherm constant $\left(n_{\mathrm{T}}\right)$ indicates the WGSAB surface is heterogeneous in nature. The maximum adsorption capacity predicted by Toth isotherm of BV3 $\left(66.699 \mathrm{mg} \mathrm{g}^{-1}\right)$ is higher than BR2 (50.310 $\left.\mathrm{mg} \mathrm{g}^{-1}\right)$. Therefore, WGSAB is more suitable for removal of BV3 than BR2. Figure 6 illustrates the comparisons of the isotherm data.

The data presented in Table 2 compare the maximum monolayer adsorption capacity of the different types of adsorbents used for the removal of BR2 and BV3. The value of $\left(q_{\mathrm{m}}\right)$ in this study is moderately larger than those in most of the previous work.

\section{Kinetics}

The determined parameter set, $R^{2}$ and RMSE values for each kinetic model are presented in Table 3. On comparison of the selected models, the higher values of $R^{2}$ and smaller values of RMSE over the selected concentration range show Avrami model correlated the kinetic data better than Ho model. It is also seen from the Table 3 that while the concentration increased the rate constant $\left(K_{\mathrm{A}}\right)$ values subsequently decreased and uptake capacity $\left(q_{e, \mathrm{~A}}\right)$ increased. Further, the fractional order $\left(n_{\mathrm{A}}\right)$ and rate constant $\left(K_{\mathrm{A}}\right)$ values are almost similar for every concentration in both the dyes. This meant that the higher concentration
Table 2 Comparison of maximum adsorption capacities for BV3 and BR2 adsorption

\begin{tabular}{lll}
\hline Adsorbent & $q_{\mathrm{m}}$ & References \\
\hline BV3 adsorption & & \\
Coniferous pinus bark & 32.78 & Ahmad (2009) \\
Calotropis procera leaf & 4.14 & Ali and Muhammad (2008) \\
Orange peel & 14.3 & Annadurai et al. (2002) \\
Palm kernel fiber & 78.9 & El-Sayed (2011) \\
Sugarcane dust & 3.8 & Ho et al. (2005) \\
Neem sawdust & 3.8 & Khattri and Singh (2000) \\
Wood apple & 19.8 & Jain and Jayaram (2010) \\
Coir pith & 2.56 & Namasivayam et al. (2001a) \\
Treated coir pith & 94.7 & Namasivayam et al. (2001b) \\
Japonica & 82.83 & Wang et al. (2008) \\
Rice bran & 42.25 & Wang et al. (2008) \\
Wheat bran & 80.37 & Wang et al. (2008) \\
Treated waste cotton seed & 66.69 & This study
\end{tabular}

BR2 adsorption

$\begin{array}{lll}\text { Treated olive stone } & 526.3 & \text { Aziz et al. (2009) } \\ \text { Spent bleaching earth } & 194.8 & \text { Mana et al. (2007) } \\ \text { Natural zeolite } & 0.055 & \text { Qiu et al. (2009) } \\ \text { Treated waste cotton seed } & 50.11 & \text { This study }\end{array}$

favored the uptake of both the dyes but led unavailability of active sites to the dye molecules (Aziz et al. 2009; Jain and Jayaram 2010).

\section{Thermodynamics}

Thermodynamic parameters including the changes in Gibbs free energy $\Delta G^{0}\left(\mathrm{~J} \mathrm{~mol}^{-1}\right)$, enthalpy $\Delta H^{0}\left(\mathrm{~J} \mathrm{~mol}^{-1}\right)$ and entropy $\Delta S^{0}\left(\mathrm{~J} \mathrm{~mol}^{-1} \mathrm{~K}^{-1}\right)$ must be considered to illustrate spontaneity of the adsorption process (Smith and Van Ness 1987). The values of enthalpy and entropy changes were obtained from Fig. 7 and are given in Table 4. As seen, the adsorption of dyes by WGSAB was spontaneous with the negative values of $\Delta G^{0}$ (Eren et al. 2010). The value of $\Delta H_{0}$ was positive which described that the dyes adsorption was endothermic and chemisorptive (Vinod and Aniruthan 2001). The positive $\Delta S^{0}$ indicated the some structural changes in the WGSAB particles as well as dye molecules during the adsorption process (Senthilkumaar et al. 2006).

\section{Regeneration}

The production charge for WGSAB is only based on the sulfuric acid cost as immature cotton seeds are naturally available in plenty. The cost of WGSAB can be further reduced if it could be regenerated for further use. From 
Table 3 Optimum parameters and statistical values for kinetics

\begin{tabular}{|c|c|c|c|c|c|c|c|c|c|c|c|}
\hline \multirow[t]{2}{*}{ Model } & \multirow[t]{2}{*}{ Parameter } & \multicolumn{6}{|l|}{ BR2 } & \multicolumn{4}{|l|}{ BV3 } \\
\hline & & $\begin{array}{l}100 \\
\left(\mathrm{mg} \mathrm{l}^{-1}\right)\end{array}$ & $\begin{array}{l}150 \\
\left(\mathrm{mg} \mathrm{l}^{-1}\right)\end{array}$ & $\begin{array}{l}200 \\
\left(\mathrm{mg} \mathrm{l}^{-1}\right)\end{array}$ & $\begin{array}{l}250 \\
\left(\mathrm{mg} \mathrm{l}^{-1}\right)\end{array}$ & $\begin{array}{l}300 \\
\left(\mathrm{mg} \mathrm{l}^{-1}\right)\end{array}$ & $\begin{array}{l}100 \\
\left(\mathrm{mg} \mathrm{l}^{-1}\right)\end{array}$ & $\begin{array}{l}150 \\
\left(\mathrm{mg} \mathrm{l}^{-1}\right)\end{array}$ & $\begin{array}{l}200 \\
\left(\mathrm{mg}^{-1}\right)\end{array}$ & $\begin{array}{l}250 \\
\left(\mathrm{mg} \mathrm{l}^{-1}\right)\end{array}$ & $\begin{array}{l}300 \\
\left(\mathrm{mg} \mathrm{l}^{-1}\right)\end{array}$ \\
\hline \multirow[t]{4}{*}{ Ho } & $\begin{array}{c}k_{\mathrm{Ho}}\left(\mathrm{g} \mathrm{mg}^{-1}\right. \\
\left.\min ^{-1}\right)\end{array}$ & 0.011 & 0.004 & 0.002 & 0.002 & 0.001 & 0.011 & 0.004 & 0.002 & 0.002 & 0.001 \\
\hline & $q_{\mathrm{e}, \mathrm{Ho}}\left(\mathrm{mg} \mathrm{g}^{-1}\right)$ & 10.799 & 20.671 & 31.108 & 40.710 & 49.557 & 10.799 & 20.671 & 31.108 & 40.710 & 49.557 \\
\hline & $R^{2}$ & 0.9632 & 0.9899 & 0.9749 & 0.9628 & 0.9548 & 0.9632 & 0.9899 & 0.9749 & 0.9628 & 0.9548 \\
\hline & RMSE & 1.3220 & 1.2920 & 3.0751 & 4.9106 & 6.5949 & 1.3220 & 1.2920 & 3.0751 & 4.9106 & 6.5949 \\
\hline \multirow[t]{5}{*}{ Avrami } & $n_{\mathrm{A}}$ & 0.287 & 0.269 & 0.252 & 0.240 & 0.235 & 0.287 & 0.269 & 0.252 & 0.240 & 0.235 \\
\hline & $K_{\mathrm{A}}\left(\min ^{-1}\right)$ & 0.287 & 0.269 & 0.252 & 0.240 & 0.235 & 0.287 & 0.269 & 0.252 & 0.240 & 0.235 \\
\hline & $q_{\mathrm{e}, \mathrm{A}}\left(\mathrm{mg} \mathrm{g}^{-1}\right)$ & 9.808 & 18.246 & 27.187 & 35.043 & 42.185 & 9.808 & 18.246 & 27.187 & 35.043 & 42.185 \\
\hline & $R^{2}$ & 0.9811 & 0.9931 & 0.9920 & 0.9839 & 0.9824 & 0.9811 & 0.9931 & 0.9920 & 0.9839 & 0.9824 \\
\hline & RMSE & 0.9322 & 1.0641 & 1.7326 & 3.2261 & 4.1185 & 0.9322 & 1.0641 & 1.7326 & 3.2261 & 4.1185 \\
\hline
\end{tabular}



Fig. 7 Thermodynamic graph for adsorption of BV3 and BR2 onto WGSAB

Table 4 Calculated thermodynamic parameters for adsorption of $\mathrm{BV} 3$ and BR2 onto WGSAB

\begin{tabular}{|c|c|c|c|c|c|c|}
\hline \multirow[t]{2}{*}{$T(\mathrm{~K})$} & \multicolumn{2}{|c|}{$\Delta G^{0}\left(\mathrm{~J} \mathrm{~mol}^{-1}\right)$} & \multicolumn{2}{|c|}{$\Delta H^{0}\left(\mathrm{~J} \mathrm{~mol}^{-1}\right)$} & \multicolumn{2}{|c|}{$\Delta S^{0}\left(\mathrm{~J} \mathrm{~mol}^{-1} \mathrm{~K}^{-1}\right)$} \\
\hline & BR2 & BV3 & BR2 & BV3 & BR2 & BV3 \\
\hline 293 & $-45,216$ & $-38,391$ & 678.04 & 572.67 & 156.64 & 132.98 \\
\hline 303 & $-46,783$ & $-39,721$ & & & & \\
\hline 313 & $-48,349$ & $-41,051$ & & & & \\
\hline 323 & $-49,915$ & $-42,381$ & & & & \\
\hline
\end{tabular}

Fig. 8, acetic acid was found efficient to elute BR2 as well as BV3 than other solvents. It was noticed from laboratory batch experiments that BR2 adsorbed WGSAB could be regenerated twice efficiently for further use using acetic acid. But the BV3 adsorbed WGSAB could be regenerated three times for subsequent experiments.

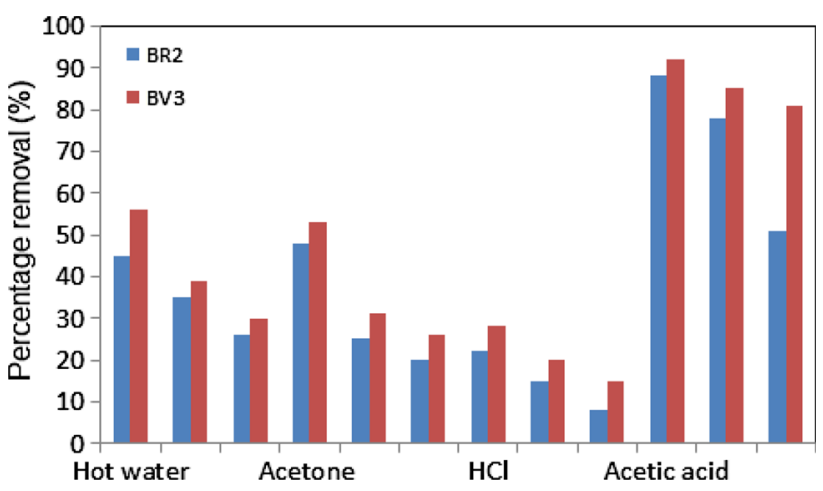

Fig. 8 Comparison of regeneration cycles

\section{Conclusions}

An adsorbent was prepared from waste Gossypium hirsutum seed and its efficiency to adsorb BR2 and BV3 was evaluated. Surface characterization of the adsorbent indicated that it has good number of pores, surface functional groups and adsorption capacity. The effects of process conditions such as initial dye concentrations, contact time, $\mathrm{pH}$ and temperature on dye removal efficiency were studied. Isotherm analysis indicated that Toth isotherm properly correlated the adsorption data and WGSAB surface is heteroporous. Kinetic modeling showed that selected cationic dyes were chemisorbed on the WGSAB surface and obeyed Avrami fractional order kinetics and higher concentrations favored the dye adsorption. Thermodynamic study indicated that desorption of BR2 and BV3 onto WGSAB was spontaneous and endothermic in nature. Regeneration of WGSAB was tried using different elutants and could be possible using acetic acid. 
Open Access This article is distributed under the terms of the Creative Commons Attribution 4.0 International License (http:// creativecommons.org/licenses/by/4.0/), which permits unrestricted use, distribution, and reproduction in any medium, provided you give appropriate credit to the original author(s) and the source, provide a link to the Creative Commons license, and indicate if changes were made.

\section{References}

Ahmad R (2009) Studies on adsorption of crystal violet dye from aqueous solution onto coniferous pinus bark powder (CPBP). J Hazard Mater 171:767-773

Akar ST, Yilmazer D, Celik S, Balk YY, Akar T (2013) On the utilization of a lignocellulosic waste as an excellent dye remover: modification, characterization and mechanism analysis. Chem Eng J 229:257-266

Ali H, Muhammad SK (2008) Biosorption of crystal violet from water on leaf biomass of Calotropis procera. Journal of Environmental Science and Technology 1:143-150

Amran M, Salleh M, Mahmoud DK, Azlina W, Karim WA, Idris A (2011) Cationic and anionic dye adsorption by agricultural solid wastes: a comprehensive review. Desalination 280:1-13

Annadurai Juang RS, Lee DJ (2002) Use of cellulose-based wastes for adsorption of dyes from aqueous solutions. J Hazard Mater 92:262-274

Arslan M, Yiğitoğlu M (2008) Use of methacrylic acid grafted poly (ethylene terephthalate) fibers for the removal of basic dyes from aqueous solutions. J Appl Polym Sci 110:30-31

Aziz A, Ouali MS, Elandaloussi EH, De Menorval LC, Lindheimer M (2009) Chemically modified olive stone: a low-cost sorbent for heavy metals and basic dyes removal from aqueous solutions. J Hazard Mater 163:441-447

Boehm HP (1966) Functional groups on the surfaces of solids. Angew Chem 5:533-544

El-Sayed GO (2011) Removal of methylene blue and crystal violet from aqueous solutions by palm kernel fiber. Desalination 272:225-232

Eren E, Cubuk O, Ciftci H, Eren B, Caglar B (2010) Adsorption of basic dye from aqueous solutions by modified sepiolite: equilibrium, kinetics and thermodynamics study. Desalination 252:88-96

Farah JY, El Gendyand NS, Farahat LA (2007) Biosorption of astrazone blue basic dye from an aqueous solution using dried biomass of Baker's yeast. J Hazard Mater 148:402-408

Freundlich H (1932) The adsorption of gases by solids. A general discussion. T Faraday Soc 28:129-130

Garg VK, Amita M, Kumar R, Gupta R (2004) Basic dye (methylene blue) removal from simulated wastewater by adsorption using Indian Rosewood sawdust: a timber industry waste. Dyes Pigments 63:243-250

Gulnaz O, Kaya A, Matyarand F, Arikan B (2004) Sorption of basic dyes from aqueous solution by activated sludge. J Hazard Mater 108:183-188

Gupta VK, Suhas (2009) Application of low cost adsorbents for dye removal-a review. J Environ Manage 90:2313-2342

Ho YS (2006) Second-order kinetic model for the sorption of cadmium onto tree fern: a comparison of linear and non-linear methods. Water Res 40:119-126

Ho YS, McKay G (2003) Sorption of dyes and copper ions onto biosorbents, process biochemistry. Process Biochem 38:1047-1061

Ho YS, Chiu WT, Wang CC (2005) Regression analysis for the sorption isotherms of basic dyes on sugarcane dust. Bioresour Technol 96:1285-1291
Jain S, Jayaram RV (2010) Removal of basic dyes from aqueous solution by low-cost adsorbent: Wood apple shell (Feronia acidissima). Desalination 250:921-927

Kasaoka S, Sakata Y, Tanaka E, Naitoh R (1989) Design of molecular-sieve carbon. Studies on the adsorption of various dyes in the liquid phase. Int Chem Eng 29:734-742

Khattri SD, Singh MK (2000) Colour removal from synthetic dye wastewater using a bioadsorbent. Water Air Soil Poll 120:283-294

Langmuir I (1918) The adsorption of gases on plane surfaces of glass, mica, and platinum. J Am Chem Soc 40:1361-1403

Malik PK (2003) Use of activated carbons prepared from sawdust and rice-husk for adsorption of acid dyes: a case study of acid yellow 36. Dyes Pigments 56:239-249

Mana M, Ouali MS, De Menorval LC (2007) Removal of basic dyes from aqueous solutions with a treated spent bleaching earth. J Colloid Interface Sci 307:9-16

Namasivayam C, Kumar MD, Selvi K, Begum RA, Vanathi T, Yamuna RT (2001a) 'Waste'coir pith - a potential biomass for the treatment of dyeing wastewaters. Biomass Bioenerg 21:477-483

Namasivayam C, Radhika R, Suba S (2001b) Uptake of dyes by a promising locally available agricultural solid waste: coir pith. Waste Manage 21:381-387

Nomanbhay MS, Palanisamy K (2005) Removal of heavy metal from industrial waste using chitosan coated oil palm shell charcoal. Electron J Biotech 8:43-48

Qiu H, Lv L, Pan BC, Zhang QJ, Zhang WM, Zhang QX (2009) Critical review in adsorption kinetic models. Journal of Zhejiang University Science A. 10:716-724

Rafatullah M, Sulaiman O, Hashim R, Ahmad A (2010) Adsorption of methylene blue on low-cost adsorbents: a review. J Hazard Mater 177:70-80

Ramaraju B, Manoj Kumar Reddy P, Subrahmanyam C (2014) Low cost adsorbents from agricultural waste for removal of dyes, environmental progress and sustainable energy. Environ Prog Sustain 33:38-46

Rangabhashiyam S, Anu N, Nandagopal MSG, Selvaraju N (2014) Relevance of isotherm models in biosorption of pollutants by agricultural byproducts. J Environ Chem Eng 2(1):398-414

Rangabhashiyam S, Anu N, Selvaraju N (2013) Sequestration of dye from textile industry wastewater using agricultural waste products as adsorbents. J Environ Chem Eng 1(4):629-641

Senthilkumaar S, Kalaamani P, Subburaam CV (2006) Liquid phase adsorption of crystal violet onto activated carbons derived from male flowers of coconut tree. J Hazard Mater 136:800-808

Sepúlveda-Cuevas LA, Contreras-Villacura EG, Palma-Toloza CL (2008) Magellan peat (Sphagnum magallanicum) as natural adsorbent of recalcitrant synthetic dyes. J Soil Sci Plant Nutr 8:31-43

Singh DK, Srivastava B (2001) Basic dye removal from wastewater by adsorption on rice husk carbon. Indian J Chem 8:133-139

Sivarajasekar N (2007) Hevea brasiliensis-a biosorbent for the adsorption of $\mathrm{Cu}$ (II) from aqueous solutions. Carbon Lett 8:199-206. doi:10.5714/CL.2007.8.3.199

Sivarajasekar N (2014) Biosorption of cationic dyes using waste cotton seeds Ph.D Thesis, Anna University Chennai, India

Sivarajasekar N, Balakrishnan V, Baskar R (2009) Biosorption of an azo dye from aqueous solutions onto spirogyra. Univ J Chem Technol Metal 44:157-164

Sivarajasekar N, Baskar R (2013) Adsorption of basic red 9 onto activated carbon derived from immature cotton seeds: isotherm studies and error analysis. Desalin Water Treat. doi:10.1080/ 19443994.2013.834518

Sivarajasekar N, Baskar R (2014a) Adsorption of basic magenta II onto $\mathrm{H} 2 \mathrm{SO} 4$ activated immature Gossypium hirsutum seeds: 
Kinetics, isotherms, mass transfer, thermodynamics and process design. Arabian J Chem. doi:10.1016/j.arabjc.2014.10.040

Sivarajasekar N, Baskar R (2014b) Adsorption of basic red 9 on activated waste Gossypium hirsutum seeds: process modeling, analysis and optimization using statistical design. J Ind Eng Chem 20:2699-2709

Sivarajasekar N, Baskar R (2015a) Agriculture waste biomass valorisation for cationic dyes sequestration: a concise review. J Chem Pharm Res 7(9):737-748

Sivarajasekar N, Baskar R (2015b) Biosorption of basic violet 10 onto activated Gossypium hirsutum seeds: batch and fixed-bed column studies Chinese. Chin J Chem Eng 23:1610-1619

Sivarajasekar N, Srileka S, Samson Arun prasath S, Rabinson S (2008) kinetic modeling for biosorption of metylene blue onto H3PO4 activated Acacia Arabica. Carbon Lett 9:181-187. doi:10.5714/CL.2008.9.3.181
Smith JM, Van Ness HC (1987) Introduction to chemical engineering thermodynamics. McGraw-Hill, Singapore

Srinivasan A, Viraraghavan $\mathrm{T}$ (2010) Decolourization of dye wastewaters by biosorbents: a review. J Environ Manage 91:1915-1929

Toth J (1971) State equations of the solid gas interface layer. Acta Chemica Acadamia Hungary 69:311-317

Vinod VP, Aniruthan TS (2001) Sorption of tannic acid on zirconium pillared clay. J Chem Technol Biotechnol 77:92-101

Wang XS, Zhou Y, Jiang Y (2008) Removal of Methylene Blue from aqueous solution by non-living biomass of marine algae and freshwater macrophyte. Adsorption Sci Technol 26:853-863 